\title{
CONSIDERACIONES SOBRE LA ESTÉTICA LITERARIA CHINA EN LA EDAD MODERNA. ECOS Y REFLEJOS DEL DAO.
}

\author{
JOSÉ MARÍA CABEZA LAINEZ \\ Universidad de Sevilla
}

\begin{abstract}
Resumen
Para la mayoría de los académicos de Cultura China, al menos hasta los tiempos del Dr. Sun Yat-Sen, el tema de la estética se presenta como un laberinto en el sentido metafórico y temporal. El erudito y escritor argentino Jorge Luis Borges plantea acertadamente este tema en su famoso cuento "El jardín de los senderos que se bifurcan", que también se encuentra en la ciudad china de Qingdao. Borges presenta a un escritor ficticio Ts'uiPên que evita la mera mención del concepto de Tiempo a través de su novela incompleta, precisamente para revelar que esta noción que falta es todo lo que importa. Un paralelismo inmediato surge con la novela de WuJingzi Los mandarines, cuyo verdadero título es La Historia no oficial del bosque de los letrados, y en el que las vidas son árboles que ocurren en una especie de bosque imaginario o laberinto natural.
\end{abstract}

Palabra clave

Literatura china, Arte, Estética, Razón Barroca

\section{SOME REMARKS ON CHINESE AESTHETICS IN MODERN LITERATURE. ECHOES AND REFLECTIONS OF THE DAO.}

Abstract

For a majority of academics on Chinese Cultureat least until the times of Dr. Sun YatSen the issue of aesthetics presents itself as a labyrinth in the metaphoric and in the temporal sense as well.The Argentinian erudite and writer Jorge Luis Borges aptly poses such matter in his celebrated tale "The garden of divergent paths" which is also located in China in the city of QingDao. Borges presents a fictional writer Ts'uiPên who avoids the mere mention of the concept of Time through his incomplete novel precisely to reveal that this missing notion is all that matters. An immediate parallel with the paramount novel "The Scholars" by Wu Jingzi arouses to the mind of the present author, especially when he recalls that the real Chinese title of the book is "The Unofficial History of the Forest of Scholars" stressing the fact that lives are trees that happen in a sort of imaginary forest or natural labyrinth.

\section{Keywords}

Chinese Literature, Art, Aesthetics, Baroque reason

Para la mayoría de los estudiosos, la estética china, al menos hasta la época del Dr. Sun YatSen, aparece como un verdadero "laberinto", metafórico y sobre todo temporal. 
Al recordar un relato del conocido japonófilo Jorge Luis Borges, tal deducción nos asalta inmediatamente

"El jardín de senderos que se bifurcan es una enorme adivinanza, o parábola, cuyo tema es el tiempo; esa causa recóndita le prohíbe la mención de su nombre. Omitir siempre una palabra, recurrir a metáforas ineptas y a perífrasis evidentes, es quizá el modo más enfático de indicarla. Es el modo tortuoso que prefirió, en cada uno de los meandros de su infatigable novela, el oblicuo Ts'uiPên. (...) no emplea una sola vez la palabra tiempo. La explicación es obvia:"El jardín de senderos que se bifurcan" es una imagen incompleta, pero no falsa, del universo tal como lo concebía Ts'uiPên. A diferencia de Newton y de Schopenhauer, no creía en un tiempo uniforme, absoluto. Creía en infinitas series de tiempos, en una red creciente y vertiginosa de tiempos divergentes, convergentes y paralelos. Esa trama de tiempos que se aproximan, se bifurcan, se cortan o que secularmente se ignoran, abarca todas la posibilidades."

En la conocida obra “Relatos del bosque de los Letrados" 儒林外史de WuJingzi podemos reconocer muchos de esos extremos pues, dentro de tal laberinto literario, la miríada de personajes que lo pueblan, se encuentran perdidos y no parecen encontrar jamás su camino moral, ni tampoco una forma de vivir con paz y serenidad.

$\mathrm{Al}$ respecto existe un nudo fundamental de la obra en el que se narra con extremo detalle la construcción y consagración del Templo del sabio WuTaibo, a juzgar por esos capítulos se diría que la restauración de la moral confuciana, resulta ser una tabla de salvación en medio de tanta molicie y degradación.

Sin embargo, en el posterior desenlace ese empeño se tornará fútil, el templo es abandonado, el amor no resulta correspondido, y nada perdura, todo es dominado por el Tiempo. Son las Ruinas de un Sueño, el sueño fallido del Humanismo en la China de Qing.

Veamos a manera de ejemplo unos fragmentos de la obra que explican tales conclusiones,

"Ahí a mano izquierda, en la Terraza de las Flores de la Lluvia, está el templo de Taibo, erigido con fondos del señor Chi, de Jurong. ¡Qué bullicio el día que fue el doctor Yu a hacer las ofrendas! Yo tenía a la sazón veinte años cumplidos, y me escurrí para mirar, y perdí el gorro en el tumulto. Pero hoy no hay quien cuide del templo y se está cayendo a trozos.

¡Pensar que tan notorio lugar iba a ser todo ruinas y que no haya quien lo repare! ¡Que todos esos ricos gasten las onzas a millares en levantar monasterios buddhistas y taoístas y ni uno solo las dé para componer el templo de un sabio!"”.

En este caso, el narrador/autor nos sugerirá que el centro del laberinto o por así decirlo, la única redención posible, consiste en la renuncia a todos los valores mundanos. Lo que puede suponer una enseñanza implícita acerca dela supremacía del WuWei无为, es decir, la no acción o el vacío creativo, noción predominante en la época de WuJingzi.

Este concepto equivaldría modernamente a dejar "estar" algo, dejar pasar el Tiempo o en palabras de Zhuangzi permitir al Tiempo/Cosmos gobernar².

\footnotetext{
1 WuJingzi (2007): 643-644.

${ }^{2}$ En los días antiguos, Shun preguntó una vez a Yao, “¿Regente del Cielo, cuál es el designio de vuestra mente?"

"Yo no desdeño a los infortunados, no postergo a los pobres, me lamento por aquelllos que mueren; siento afecto por los huérfanos y simpatía por las viudas," replicó Yao.

"Encomiable, pero no es esta la verdadera grandeza," dijo Shun

“¿Qué debería hacer entonces?” preguntó Yao.

"La virtud del cielo en acción produce quietud. El sol y la luna brillan y las cuatro estaciones siguen su curso. El día y la noche mantienen su orden constante, y cuando las nubes se congregan, cae la lluvia", contestó Shun.

“¡Entonces he causado sólo aflicción! Vos aspiráis a estar en armonía con el Cielo mientras que yo lucho por estar en armonía con los Hombres", dijo Yao.

Desde la antigüedad, el cielo y la tierra han sido considerados grandes. El Emperador Amarillo, Yao y Shun los veneraron. ¿Cómo actuaron los reyes antiguos? Dejando al cielo y a la tierra gobernar. Zhuangzi. Capítulo 13
}

昔者舜問於堯曰：「天王之用心何如？」

堯曰:「吾不敖無告，不廢窮民，苦死者，嘉孺幾而哀婦人，此吾所以用心已。」

舜曰:「美則美矣，而未大也。」 


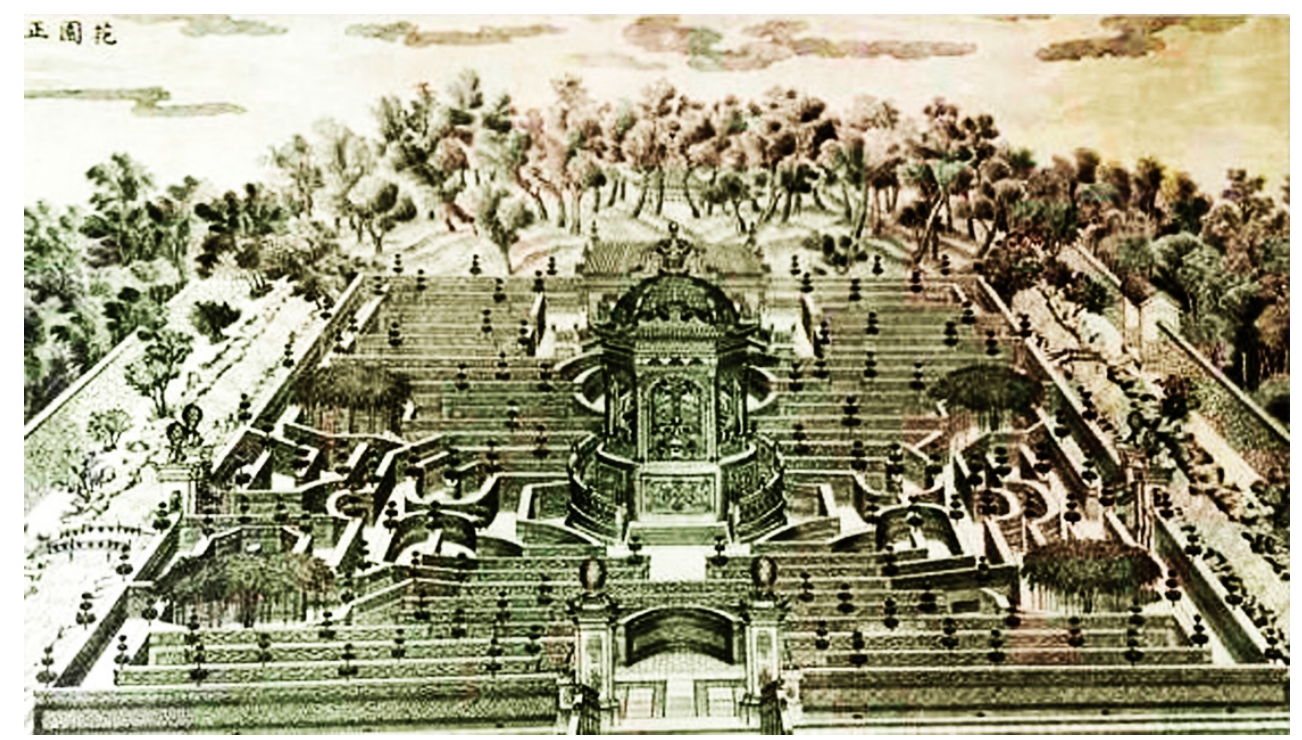

Fig.1. Jardines de Yuan Ming Yuan, Beijing.

1783-86. Giuseppe Castiglione

El famoso erudito polaco ZbigniewSlupski nos comenta la afirmación de H. C. Chang sobre quela integridad de El bosque de los letrados se basa en el tiempo subjetivo. Puede que se adopte un marco histórico y algunas fechas ciertas, como la referencia al Emperador Yongle, pero el esquema temporal se adapta a los ciclos de vida de los individuos. Sus oleadas de personajes y acontecimientos reflejan el ascenso y caída del universo chino en el que se pueden registrar los días y los meses pero la verdadera medida del tiempo es la generación. La unidad es la del rollo de pinturas, una sucesión de duraciones, variada y llena de sorpresas agradables. Y que parecen no terminar nunca, sin clímax ni anticlímax. Cien años se han detenido en un solo instante.

Este tiempo subjetivo dota al relato de cierta cohesión y para los autores citados debe ser contemplado como un logro técnico al nivel de la sátira o la picaresca en la obra, sobre la que luego incidiremos.

De hecho, el WuWei resultará fundamental para la novela, en ella continuamente se nos muestra la inutilidad de actuar, la necesidad imperiosa de refrenarse ante el sistema y confiar en la Nada, incluso aparecerá con cierta frecuencia la ciudad de WuWei, como escenario de fragmentos, por ejemplo en la plática de los geomantes del capítulo 45.

Desde el poema introductorio, lo encontramos

Famas, honras y riquezas

Sin dejar rastro se evaden,

$Y$ el que a ellas se consagra,

Malgasta su vida en balde

$Y$ hasta el olvido te embriague,

Que nadie sabe el destino

De la mustia flor errante

Abatida sobre el río,

堯曰:「然則何如？」

舜曰: 「天德而土寧, 日月照而四時行, 若書夜之有經, 雲行而雨施矣！」

堯曰: 「膠膠擾擾乎! 子, 天之合也; 我, 人之合也。」美天地者, 古之所大也, 而黃帝、 堯、舜之所共美也。故古之王天下者, 奚為哉? 天地而已矣! 
Prisionera de su cauce. ${ }^{3}$

Hasta la canción de clausura de la obra,

Cien años pasan volando

¿Por qué tanto sentimiento?

¿Tan arduo es seguir la senda

De los laureles eternos!

Con mi horno de alquimista

$Y$ mis libros para el rezo,

Al Príncipe del V acio

Honraré en lo Venidero 4

Se nos insiste en las ideas de la Impermanencia y la Nada.

Sobre ello incidirá parte de lo dicho en la página 21 al explicar la vocación pictórica de Wang Mian,

"La vida del hombre es como un lienzo, según reza certeramente el adagio de la antigüedad. Lástima que no haya pintor que dibuje esos lotos ${ }^{5}$. Mas al punto se dijo: Aunque también es cierto que no hay cosa que el hombre no aprenda. ¿Por qué no los pinto yo?”

Y luego existen muchas más alusiones, que en su contexto pueden resultar irónicas,

Truécanse de pronto en nada

Riquezas y Dignidades;

Un andador de caminos

Hace a cientos amistades. ${ }^{6}$

De las glorias y riquezas,

El Deleite dura apenas;

De la vejezy el mal sino,

La marea crece y mengua.

El viento pasa y las nubes se esparcen

$Y$ el talento y la virtud quedan en nada;

La leña se acaba y la brasa sigue

$Y$ al fin surgen otros hombres de fama. ${ }^{8}$

Una técnica importante de la novela es la motivación inversa, por la cual los hechos son modificados o incluso negados en virtud de cierta información que se revelará más tarde. Lo que una vez más nos coloca al Tiempo, o bien a lo impredecible como protagonista.

El laberinto, oscuro, caleidoscópico y fractal como veremos, es la propia Vida Humana, el Mundo o el Infierno. La salida impensable del mismo supone la Redención y la Iluminación o el Paraíso Recobrado. El laberinto es por supuesto un Mandala.

\section{Una literatura barroca}

Existe un matiz cervantino o gongorino (como diría Turgeniev hay asombrosa cantidad de Quijotes y Sanchos entre los personajes), acaso miltoniano en todo el relato de WuJingzi,

\footnotetext{
${ }^{3}$ Wujingzi (2007): 19. En este caso, en los tres últimos versos a los que hicimos referencia más arriba, nos indica que el río es el Tiempo y la flor errante el Individuo, "prisionero de su cauce".

4 WuJingzi (2007):647.

5 Wujingzi (2007): 21. La decisión de pintar lotos puede considerarse alegórica, ya que se trata de la flor sagrada del buddhismo, que crece y mantiene su singular belleza en medio del légamo y la impureza.

6 WuJingzi (2007): 331

7 WuJingzi (2007): 311

8 WuJingzi (2007): 636
} 
suponemos que por efecto de la monumental y reciente traducción de Ramírez Bellerín. Pero, aun constituyendo una referencia lejana que trataré de justificar científicamente, subrayo el paralelismo con tales autores y con el Francisco de Quevedo de Los Sueños, en particular en la obra ejemplar El mundo por de dentro.

En ella el relator se presenta a sí mismo como Desengaño y se propone conducir al lector por la calle Hipocresía donde "nada es lo que parece" y todo sucede "por debajo de cuerda", dándose en ella la mano la dama Vida con la dama Muerte.

Comparemos tan sólo este pasaje deEl bosque de los letrados:

"Y es que los oficiales de la dinastía Ming llamaban "amigos" a los licenciados, y "amiguillos" a los bachilleres. A un bachiller que hubiese pasado a licenciado se le decía "amigo", aunque tuviese menos de veinte años de edad; y al que no se graduaba de licenciado, ya podía cargar ochenta años a las espaldas, que todos los trataban de "amiguillo". Lo propio ocurría con las mujeres: al casar se las llamaba "desposadas", y ya bien cuajadas en matrimonio, "dueñas" o "señoras", pero a la concubina siempre se la trataba de "esposa nueva", aunque tuviese el pelo blanco""

... con el discurso de Desengaño de "Los Sueños":

"El zapatero de viejo se llama entretenedor del calzado, el botero, sastre del vino, que le hace de vestir; el mozo de mulas, gentilhombre de camino; el bodegón, estado, el bodegonero, contador; el verdugo, se llama miembro de la justicia y el corchete criado; el fullero, diestro; el ventero, huésped; la taberna, ermita; la putería, casa; las putas, damas; las alcahuetas, dueñas; los cornudos, honrados."10

Esto podría relacionarse con el discurso sobre los "nombres verdaderos" del Dao De Jing, que esbocé en otra obra, por lo que no vuelvo a insistir ${ }^{11}$ ahora. Pero resulta claro a mi entender que existen similitudes tanto en la forma como en el contenido.

Por ejemplo a lo largo de la obra de WuJingzi llama la atención la miseria y mezquindad de los personajes que parecen haber perdido todo resquicio de integridad moral y a cambio se debaten buscando economías o prebendas por cualquier rincón.

Es la picaresca, otro rasgo definitorio del barroco, que resulta muy acusado aquí, reforzando el carácter costumbrista de la obra y las ideas sobre las fuentes populares, su gastronomía, sus técnicas de curación, etc. En ese sentido es impagable la capacidad del autor para proveernos con texturas del folclore. En el discurso de la picaresca, los personajes están atrapados por el laberinto de sus contradicciones internas, como la flor del río en el poema introductorio $^{12}$, pero nunca parecen reflexionar sobre su miserable condición, ni lamentarse.

La obsesión perpetua consiste en optar a clasificarse socialmente tras haber superado los exámenes imperiales; aquél que lo consiga puede ya olvidarse de su deficitaria condición previa, recibirá honores y dádivas de toda índole para toda su familia, aunque sea poco más que un patán, y si se encuentra en una situación dudosa, la esquivará valiéndose de cualquier treta improvisada, a pesar de que sus errores e ignorancia hayan atraído la muerte o el infortunio sobre otros desdichados. En ese sentido me asombra la similitud con circunstancias actuales.

En algunos momentos se diría que las situaciones se aproximan o lo dantesco (nell mezzo del cammin di nostra vita), sobre todo por la ausencia de arrepentimiento o escrúpulos que denotan los personajes en su comportamiento cuasi brutal, pero si se intenta recurrir a las autoridades para frenar tanta barbarie, el resultado suele ser aún peor y acabar en desastre.

Cuando reparamos en las letrillas que va intercalando el autor, comprendemos una vez más la futilidad de las pasiones humanas; los que debían ser humanos se han convertido en brutos mecánicos.

El tipo de paradoja principalmente utilizado en "El bosque de los letrados", la inversión temporal nos recuerda al histeron-proteron o el zengma de Shakespeare.

\footnotetext{
${ }_{9}^{9}$ WuJingzi (2007): 35-36

10 Quevedo (2007): 93

11 “Los nombres que pueden darse no son los nombres verdaderos". 名可名, 非常名

12 WuJingzi (2007):19
} 
Es necesaria pues la confrontación constante y una comparación casi científica de todos los hechos presentados en el libro, independiente del lugar que ocupen en la narrativa.

\section{Carácter fractal de la obra}

Al considerar la hipótesis del laberinto, es importante entender que se trata de una figura fractal, compuesta por la repetición ordenada de pequeños segmentos o situaciones esquemáticas. Esto es precisamente lo que desconcierta en el mismo. Su simplicidad.

La mejor definición no técnica de fractal aplicada a una obra de que disponemos corresponde al novelista y compositor Francisco Guerrero.

"La fractalidad sería referirse a sí mismo, autocontenerse, crear algo a partir de unos sencillos datos iniciales, suficientes como para fabricar complejidad y riqueza. La obra involuciona, es mil veces la misma. Un instante es toda la obra y toda ella son sucesivos o infinitos instantes. La obra es un único capítulo conteniendo la totalidad."

$\mathrm{La}$ fractalidad como sabemos es igualmente una de las principales formas de producirse de la Naturaleza, de los árboles y la vegetación (de ahí trazo conexiones con El bosque de los letrados). El Barroco lo es entre otras cosas por un intento obsesivo de expresión literal de la complejidad en la Naturaleza: rocalla, follajes, grutas, montes sagrados, santos desiertos y por supuesto caleidoscopios, perspectivas falsas o ilusorios laberintos vegetales. Lost.

El laberinto es un Aleph del mundo barroco tal como presenta John Milton en Paradise

Whereon for different cause the Tempter set

Our Second Adam, in the wilderness,

To show him all Earth's kingdoms and their glory,

His eye might there command wherever stood

City of old or modern fame, the seat

Of mightiest empire, from the destined walls

Of Cambalu, seat of Cathaian Can,

And Samarcand by Oxus, Temir's throne,

To Paquin of Sinaen kings, and thence

To Agra and Lahor of Great Mogul,

Down to the Golden Chersonese, or where

The Persian in Ecbatan sat, or since

In Hispahan, or where the Russian Tsar

In Moscow, or the Sultan in Bizance,

Turkestan-born; nor could bis eye not ken

The empire of Negus to bis utmost port

Ercoco, and the less maritime kings,

Mombara and Quiloa and Melind,

And Sofala, (thought Opir), to the realm

Of Congo and Angola farthest south;

Or thence from Niger flood to Atlas mount,

The kingdoms of Almansor, Fez and Sus,

Marocco and Algiers, and Tremisen; 
On Europe thence, and where Rome was to sway

The World; in spirit perhaps he also saw

Rich Mexico, the seat of Motezume,

And Cusco in Peru, the richer seat

Of Atabalipa, and yet unspoiled

Guiana, whose great city Geryon's son

Call El Dorado; but to nobler sights

Michael from Adam's eyes the film removed. ${ }^{13}$

En "La Expansión Ibérica, Germen de la Razón Barroca", postulaba la audaz hipótesis de que el Barroco, (característica por excelencia de Europa, según afirmase el premio Nobel de Literatura Czeslaw Miłosz ${ }^{14}$ ) habría surgido a través el encuentro con las sensibilidades de los nuevos mundos, en particular América, Oriente y sobre todo China mediante los intercambios propiciados por los jesuitas.

Las presentes reflexiones, siguiendo a C. Buci-Glucskmann en La raison baroque (1984), se proponen expandir algo más tal idea.

Por tanto creo poder afirmar que esta obra resulta barroca, o al menos es un retablo o Gran Teatro del Mundo, en el sentido de que discurre sobre un juego continuo de paradojas, que a veces de tan irónicas resultan cómicas, incluso el prolijo ceremonial del Templo de WuTaibo (ver Capítulos 36 y 37) que se pretende que sea serio, con la cantidad de gestos e invocaciones que se le introducen: ¡Bajad la cabeza! Erguidla! Bajadla! Erguidla! Bajadla! Erguidla! Bajadla! y así sucesivamente, llega a convertirse en ridículo.

Por el contrario, se podrá argumentar en contra,que no hay un sustrato ideológico religioso en Los Mandarines como síque queda muy claro en gran parte de la literatura barroca europea.

Sin embargo me propongo demostrar a continuación que esta idea no sería exacta pues en realidad existe un enorme trasfondo de las religiones chinas en la obra, hasta el punto de que puede rastrearse como una de las principales líneas temáticas o "ramas" de la obra.

\section{Moral, religión o retribución kármica en "los mandarines"}

Considero que la novela de Wujingzi refleja fiel y admirablemente el gran sincretismo religioso que se da en la China de la época y que perdura hasta hoy, donde las tradiciones taoístas, buddhistas y confucianas se dan la mano y se entremezclan a su vez con elementos del folclore.

Para aclarar este punto, me gustaría detenerme algo en el Capítulo 4. Éste se consagra en su primera parte al duelo por la madre del Señor Fan y posteriormente al juicio de los mahometanos. Me parece relevante para entender algo más de la situación religiosa en China.

${ }^{13}$ La montaña sobre la cual el tentador transportó por motivo diferente a nuestro Segundo Adán en el desierto para mostrarle todos los reinos de la tierra y todas sus glorias.Desde allí, la Mirada de Adán podría dominar, en cualquier parte donde estuviesen situadas, las ciudades de fama Antigua o moderna, las capitales de los imperios más poderosos, desde los muros destinados para Cabalu residencia del Kan de Catay, y desde Samarcanda, trono de Temir, cerca del Osus, hasta Pekin, capital de los reyes de China; y desde allí, hasta Agra y Lahore, del Gran Mogol, descendiendo hasta el Quersoneso de Oro, o bien hacia el sitio que el Persa habitaba en otro tiempo en Ecbatana, o en Ispahan después, o hacia Moscú, ciudad del Zar de Rusia, o hacia Bizancio, sometida al sultán oriundo del Turquestán. Sus ojos podían ver también el imperio del Negus hasta Ercoco, su Puerto más distante, y los estados menos marítimos de Mombasa, Quiloa, Melinda y Sofala, que se cree sea Ofir, hasta el reino de Congo y el de Angola, más distantes hacia el Sur. Desde allí podía divisar, entre el valle del Niger y el monte Atlas, los reinos de Almanzor, de Fez, de Sus, de Marruecos, de Argel y de Tremecén, y en seguida, en Europa, los sitios donde Roma debía dominar el mundo. Quizá vio también representada en su espíritu la rica Méjico, asiento de Moctezuma, y en el Perú , a Cuzco, morada más rica aún de Atabalipa, y la Guyana, no despojada aún, y cuya gran ciudad fue llamada Eldorado por los hijos de Gerión.

14 A Europa la define sobre todo la arquitectura y dentro de ésta el Barroco, esa explosión que extendieron los jesuitas. 

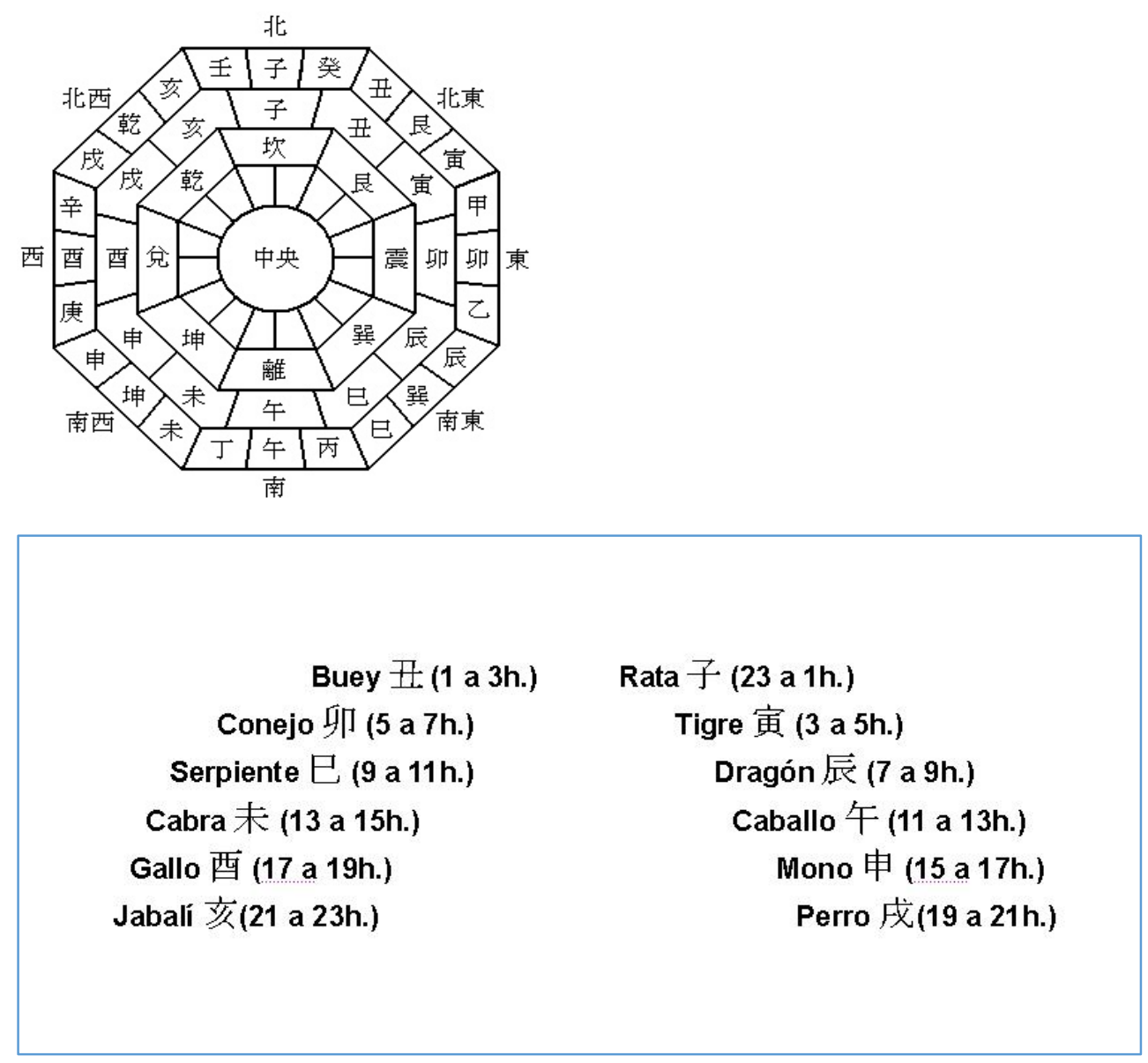

La anciana fallece justo cuando se ha puesto fin a sus miserias ${ }^{15}$. En ese momento se ha de llamar al maestro de Feng-shui o Yinyangsheng阴阳生(陰陽生), el “Amo” del Yin y el Yang que en Japón se conoció como Onmyoshi(陰陽師), quien ha de determinar las fechas y direcciones propicias en función del daoísmo, por ejemplo utilizando el color blanco en la decoración, que coincide con la dirección funesta del oeste presidida por el Tigre.

En mismo capítulo se volverá a mencionar al geomántico ${ }^{16}$ y bastante más adelante ${ }^{17}$, se hará una breve referencia al Fengshui, continuando con la cuestión de las ramas celestes apuntada al comienzo de la obra (el traductor las llama ramas terrestres) para explicar las horas o vigilias. Parece algo muy complejo pero en realidad es sólo lo que comúnmente conocemos como horóscopo chino, que se utilizaba por igual para los meses y la división del día en horas; así se nos dice que "el Maestro Zhou llega a las nueve o diez de la mañana"18. El texto original chino lo que indica es que llega a la hora de si la serpiente (sexta rama 巳 牌), que va desde las 9 hasta las 11 porque al ser doce signos, lógicamente han de cubrir dos horas cada uno.

Puesto que esa explicación me parece más útil, adjunto aquí un esquema resumen de confección propia, para indicar la división taoísta del espacio-tiempo.

Si colocáramos las atribuciones en círculo, como en una brújula de Feng Shui (vide infra) observaríamos que la Rata mira al Norte y el Caballo al Sur, por eso la puerta de entrada a

\footnotetext{
15 WuJingzi (2007):59

16 WuJingzi (2007):64

17 WuJingzi (2007):663, nota 9.

18 WuJingzi (2007):35
} 
los palacios imperiales de China se llama WuMen午门, literalmente "la puerta del Caballo", pero en español se suele traducir casi siempre por "puerta del meridiano".

Sin ánimo de extendernos sobre el particular, sino sólo para aclarar una cuestión que consideramos importante, nos gustaría hacer notar que toda la vida de la China de la dinastía Qing estaba regulada por estas determinaciones geománticas, que no se limitaban a la decoración, sino que afectaban a la música, la medicina y las Virtudes Confucianas o aspectos del Buddhismo. ${ }^{19}$

Siguiendo con la breve revisión del capítulo cuarto, podríamos añadir que se indica cómo a pesar de los dictámenes del geomántico, también es requerida la presencia y el oficio de los monjes buddhistas ${ }^{20}$ que deben ejecutar varias ceremonias y posteriormente en función de las malas artes del prefecto de los monjes, aparecen nuevos problemas para la celebración que deben ser solventados por señor Fan, mediante sobornos.

Cuando el prefecto es liberado, se coloca en la casa afectada una imagen del Buddha junto con Yama el Señor de los Infiernos, siguiendo en este caso la Geomancia de la India, que se denomina Vastu, en ella Yama domina la dirección Sur, porque es de allí de donde vienen los monzones potencialmente destructivos y por tanto la relación con el inframundo.

Más tarde ya durante el funeral los monjes deben encomendarse a las cinco direcciones y los cinco elementos según las explicaciones anteriores ${ }^{21}$ "veneraron, penitenciaron, quemaron incienso, encendieron cirios, aventaron arroz, esparcieron flores y patearon los cinco puntos cardinales."

Por ello, en ese episodio entre otros (ver por ejemplo la inauguración del templo de WuTaibo y los capítulos 44 y 45), se destacan gran cantidad de elementos de la creencia sobrenatural de China y el sincretismo religioso y así hasta la página 150 tenemos,

"El diez del mes pasado hizo la mudanza, y el prefecto y el magistrado fueron a darle parabienes y se quedaron festejando hasta la segunda o la tercera vigilia",22

"Hermano taoísta, no tuve la fortuna de verte un día que pasé por el templo de la BodhisattvaGuanyin, en mi humilde distrito" 23 .

"Hechas, las oraciones, el adivino se postró, y quemando una fórmula invocatoria, pidió a los subdirectores tuviesen la varita de sus dos cabos; leyó un encantamiento, quemó otra fórmula, ésta iluminatoria, y como la varita se agitara, mandó a un criado traer una taza de té, que presentó arrodillado al espíritu; la varita trazó unos círculos y dejó de moverse. ChenHefu quemó otra fórmula mágica, pidió silencio e hizo salir a los criados y al mayordomo de la habitación. Pasado el tiempo de un almuerzo, la varita se agitó y escribió en la arena:

19 “'Acaso el cielo se encuentra en perpetuo giro? ¿Y la tierra mora en reposo? ¿El sol y la luna se persiguen mutuamente? ¿Quién dirige y guía estos movimientos? ¿Quién los sostiene y los conecta? ¿Quién es tal que sin tensión ni esfuerzo, los produce y mantiene? ¿Existe quizás un proceso desconocido por el cual no podrían ser de otro modo? ¿O bien se mueven y giran por incapacidad de detenerse ellos mismos?”

“天其运乎? 地其处乎? 日月其争于所乎? 孰主张是? 孰维纲是? 孰居无事推而行是? 意者其 有机缄而不得已乎? 意者其运转而不能自止邪? 云者为雨乎? 雨者为云乎? 孰隆施是? 孰居无事 淫乐而劝是? 风起北方，二西一东，有上仿徨。孰嘘吸是？孰居无事而披拂是? 敢问何故? ”票咸 袺曰: “来, 吾语女。天有六极五常, 帝王顺之则治, 逆之则凶。九洛之事, 治成德备, 临照下 土, 天下戴之, 此谓上皇。”

"WuxianShao dijo: "Ven y aprende. En el cielo hay seis direcciones y cinco elementos. Cuando los emperadores y los regentes actúan de acuerdo con aquellos, surge el buen gobierno. Cuando los desafían, cunde la degradación. Observa los preceptos de los Nueve Hexagramas Luo, por los cuales el gobierno puede guiarse y la virtud se expande. Busca e ilumina todo aquello que hay bajo el cielo y todo cobrará vida. Es esto lo que otorgan los regentes augustos". Libro 14 de Zhuangzi.

20 WuJingzi (2007):60

21 WuJingzi (2007):63

22 WuJingzi (2007):21, notas 8 y 9

23 WuJingzi (2007):104 


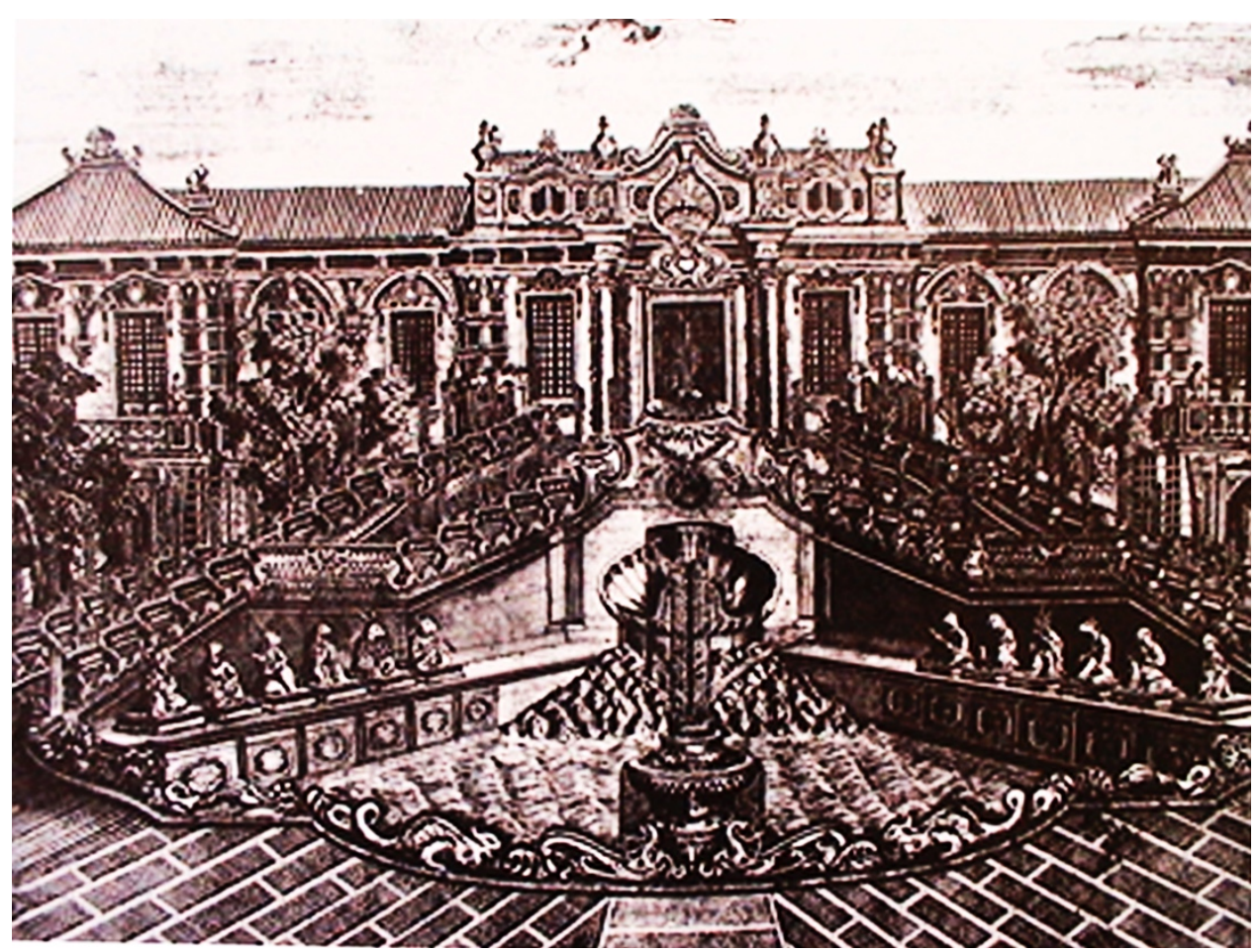

Fig. 2. Palacio del mar calmo y reloj de agua en los Jardines de Yuan Ming Yuan, Beijing. 1783-86. Giuseppe Castiglione

Escuche el oráculo el señor Wang". ${ }^{24}$

“Un día Wang Hui oyó decir a los servidores que el príncipe era el octavo hijo de la Casa Imperial, y ahí cayó en cuenta que las cítaras 琴瑟 y laúdes 琵琶 de que hablaba el oráculo del Divino Emperador Guanyu no quería decir otra cosa que "Octavo Príncipe", ya que en su escritura se repetía ocho veces el carácter, que significa "príncipe" 王 con ello el vaticinio quedaba del todo desentrañado" 25

(Es interesante destacar en este último fragmento profético que se utiliza la propia grafía como una especie de sistema jeroglífico lo que nos parece una cierta clave interna del autor)

"Al cabo, el compilador, narró la consulta al oráculo de Wang Hui, de la cual nada sabían los hermanos". ${ }^{26}$

“QQué día se colgó el arco a la puerta de su casa? El dieciséis de la tercera luna. El compilador Lu asintió con la cabeza, grabando bien la fecha" $"$.

"Algo sé de la ciencia de los hexagramas, de astrología, adivinación, medicina interna, cirugía, alquimia interna y externa, espiritismo y oráculos - dijo ChenHefu-. En la capital soy frecuente convidado de los ministros de los Consejos y los oficiales de las Cuatro Grandes Escribanías, y no hay predicción mía que no se cumpla." ${ }^{2}$

Consideramos que todo este trasfondo moral y simbólico comparable a la Qabala, nos introduce en las ideas de retribución kármica, ajuste natural o justicia poética, todas ellas

\footnotetext{
24 WuJingzi (2007):105-106

25 Wujingzi (2007):115.

26 WuJingzi (2007):139

27 Wujingzi (2007):140

28 WuJingzi (2007):141
} 
comunes al sincretismo Buddhista-Taoista (el escritor japonés Okakura, en "The Book of Tea" equiparará en 1905, Buddhismo Zen con Taoismo)

Al fin y al cabo, como vimos en los libros 13 y 14 de Zhuangzi, la geomancia es un sistema de organización del Cosmos, la disposición de las estrellas, el orden del Universo, es el que debe regir los asuntos humanos a fin de evitar la catástrofe. La verdadera justicia es la que otorga el Cielo, el ser humano no puede sino imitarla torpemente. El laberinto es un reflejo de ese cosmos fractal y en apariencia incomprensible, infinito o abigarrado dentro de su gran simplicidad.

Si volvemos al muy representativo capítulo 4, en él aparece un episodio, en el cual el magistrado Tang pregunta a Zhang Jingzhai ${ }^{29}$, sobre la conveniencia de aceptar o no un regalo de carne de buey, ya que los habitantes son predominantemente musulmanes y es la única carne que se les permite comer.

Zhang recomienda que se castigue al anciano que hace el regalo mediante la canga y el castigo es tan severo y grotesco que le provoca la muerte, con lo cual se organiza un tremendo tumulto y el señor Zhang se ve obligado a huir ignominiosamente descolgándose por la muralla mediante cuerdas. ${ }^{30}$

Las pasiones negativas, los castigos y torturas son muy frecuentes en la obra y han tenido gran trascendencia en toda la literatura posterior, como luego aduciré. Baste recordar por el momento la novela Le Jardin des Supplices de Octave Mirbeau (1899), que se desarrolla en China.

Posteriormente, Zhang se verá obligado por el comisario de justicia ${ }^{31}$ a despachar con los mahometanos e incluso aparece otro relato de un cerdo fugitivo que tiene que ver una vez más con geomancias (un episodio similar aparece reflejado en la reciente película El último viaje del juez Feng de LiuJie, 2006).

Se diría por ello que los que profesan una religión diferente de la norma van a ser poco tolerados, experimentando con frecuencia el infortunio y la ausencia de justicia favorable.

Por lo demás las críticas a los geomantes son extensas en los Capítulos 44 y 45 pero indican hasta qué punto era común su oficio.

Además tales ideas sobre la retribución y la hipocresía referidas a la relación entre los poderosos y el pueblo fueron descritas en el Zhuangzi (Zeyang Libro 25) y asombra comprobar su estrecho paralelismo con la época actual.

古之君人者，以得为在民，以失为在已; 以正为在民，以枉为在已。故一形有 失其形者, 退而自责。今则不然, 喏为物而愚不识, 大为难而罪不敢, 重为任而 罚不胜, 远其涂而诛不至。民知力竭, 则以伪继之。日出多伪, 士民安取不伪。 夫力不足则伪，知不足则欺，财不足则盗。盗窃之行，于谁责而可乎?”

"Los antiguos dirigentes creían que el éxito del gobierno residía en el pueblo y el fracaso en ellos mismos. Por lo tanto, conque una sola persona perdiese la vida eran capaces de aceptar su responsabilidad y retirarse. Pero ahora es diferente. Los dirigentes actuales ocultan lo que debe hacerse y desprecian al pueblo llamándole ignorante cuando no les comprende. Infligen dificultades a los ciudadanos y los denuncian cuando no pueden superarlas. Imponen cargas excesivas y castigan a aquellos que se rebelan; fuerzan a los ciudadanos a trabajar hasta la extenuación y si no pueden continuar son remplazados. Cuando la gente ha llegado al límite de su capacidad y de sus fuerzas cae en el engaño. Si los dirigentes recurren a la hipocresía a diario, ¿cómo será que los funcionarios y el pueblo no se han de volver hipócritas?"

"Cuando la resistencia es insuficiente, la hipocresía aumenta; cuando el conocimiento no es suficiente surge la decepción; cuando escasean los bienes se incrementa el robo. ¿A quién deberíamos entonces culpar por tales actos de asalto y piratería?"

Ya lo habían anticipado 1000 años antes y Wu parece ignorarlo, los grandes historiadores chinos司馬相如Sima Xiangru y 曹子文 Cao ZiWen al decir que, “la verdadera belleza de

\footnotetext{
${ }^{29}$ WuJingzi (2007):68

${ }^{30}$ Wujingzi (2007):71

31 WuJingzi (2007):72
} 
una capital consiste más en las caras felices de sus gentes que en las torres y los ornamentos que hay encima de los edificios."

Por lo demás, la discusión sobre conceptos sobrenaturales y mágicos nos llevará a la siguiente línea temática, el tratamiento del misterio y la fantasía en la obra:

\section{Fantasías y sueños}

En el prólogo del Viejo del Pabellón, se critican los prodigios de obras tan famosas como La Peregrinación al Oeste o JinPingMei; se nos indica que ésta va a ser una obra basada en el realismo y que no hay por qué buscar sucesos extraordinarios valiéndose de la fantasía pues la realidad es con frecuencia más asombrosa y mucho más estremecedora.

La novela supone por ello un avance para la literatura china, en el sentido de que la fantasía parece muy alejada, como prueba la amarga sentencia al descubrirse el fraude del ermitaño: " $Y Y a$ no existen inmortales en el Mundo!"”2

Sin embargo hasta cierto punto el nivel de ficción sigue siendo deseable, pues como expone el crítico literario Rodolfo Machado, "las ficciones son testimonio de la aspiración por otra realidad, una realidad que es diferente de la que vemos; la retórica sirve para que el lector desee aquello que se ha imaginado..." "¿Acaso no deseamos que lo aún no existente llegue a ser?"

Es suficiente recordar la importancia social de la ficción tal como la describe LiangQichao en 1902.

Los elementos de fantasía que no huyen del realismo, se introducen en el relato mediante sueños proféticos o premonitorios. El ejemplo más claro es el de XunMei.

Éste aparece por primera vez en el Capítulo 2 cuando tiene seis años de edad. Pide a ZhouJin que evalúe su pergamino con un ejercicio y es observado por Wang Hui a quien llama la atención el nombre que aparece en la hoja de papel. Wang está entusiasmado por su descubrimiento pues ha tenido un sueño en el que supera los exámenes metropolitanos en compañía de un hombre llamado XunMei.

Más tarde, resurge en el capítulo 7, donde se le menciona repetidas veces: a pesar de los muchos años que han pasado ZhouJin aconseja a Fan Jin que preste atención a XunMei durante el examen. Lo supera con creces y comprobamos que se ha se ha convertido en un joven atractivo.

$\mathrm{Al}$ año siguiente pasa el examen provincial, y poco después el metropolitano. Entonces recibe la visita de Wang Hui que como se profetizó en el sueño ha superado el examen con XunMei. Posteriormente XunMei se muda a la casa de Wang Hui y al oír que su madre ha muerto acepta el consejo de Wang Hui de ocultar tal hecho y solicitar ser liberado del período obligatorio de tres años de luto que pospondría su nominación paraun puesto estatal. Sin embargo la petición es rechazada y XunMei vuelve a su pueblo, sin volver aparecer "físicamente" en la historia.

Luego volveremos a oír hablar de él como alguien que alcanza una gran posición en el próspero negocio de la sal, su inteligencia y sabiduría son elogiadas.

El elemento del sueño es por supuesto muy revelador y común a toda la literatura barroca, sueños de Calderón y Quevedo, el Sueño del Pabellón Rojo de Cao Xueqin, el sueño de la mariposa de Zhuangzi destacado por Voltaire. Sueños de laberintos de los que no es posible escapar, donde Shakespeare tal vez se acerca para susurrarnos: "to die, to sleep, per chance to dream."

Eso nos conduce a la siguiente línea temática, la biografía de personajes.

\section{Genealogía. Personajes en los mandarines}

Hay una enorme variedad de personajes en la obra aunque la mayoría obedecen a los mismos patrones, letrados, aspirantes a letrados o bien siervos, clérigos y mujeres

\footnotetext{
32 WuJingzi (2007):197
} 
relativamente al margen del asunto; más adelante me referiré al amor y los personajes femeninos.

Si bien, debido a que aún no existe en la obra Monólogo Interior, poco sabemos de las intimidades de los protagonistas pues estos sólo se manifiestan mediante el diálogo o la interacción aunque sea por vía oracular con otros intervinientes.

Ello contrasta abiertamente con obras actuales como la de GaoXingJiang, sobre todo en El libro de un hombre solo donde toda la acción transcurre prácticamente dentro de la mente y en sus recuerdos" por lo que no hacen falta contextos geográficos o efemérides que sí son continuas en Los Mandarines.

Me inclino a pensar que "El bosque de los letrados" es casi un árbol genealógico (El bosque...), o retomando la discusión geomántica me atrevo a decir que es como un Mandala de personajes relevantes en la época a los que por alguna razón (falta de pago o desesperación) el autor decidió caricaturizar y estereotipar para mostrar su protesta. Este mandala es obviamente centrífugo y dinamógeno pues no representa sino el laberinto del mundo.

Se dice que los personajes no son particularmente buenos o malos, pero a diferencia de lo que reclamaba Aristóteles en Poetika para la tragedia, aunque cometan tremendos errores, nunca caen en el infortunio, por lo tanto la obra relata sucesos terribles que no provocan ni temor ni compasión en el lector, antes mueven a la hilaridad.

Creo que la característica principal de los personajes es su completa falta de miras o aún más claramente su propensión a la Crueldad innecesaria a la Brutalidad, y la Estupidez.

Las referencias a las varas de castigo, el famoso "bastinado" del que tanto hablara Spence (que podía causar la muerte a partir de un cierto número de golpes y desde luego graves secuelas), las cangas y otros tormentos, así lo atestiguan y dan pie a que se divulgue una idea hasta cierto punto fundada sobre la refinada crueldad de los mandarines chinos, que alcanzará su apogeo en obras citadas anteriormente como Le Jardin des Supplices de Octave de Mirbeau.

Un mundo así, tal como nos muestra Wu en todo su crudo realismo, incitaría a cualquier tipo de Rebelión Violenta, pues después de leerlo no quedaría nadie sin el "Alma rota a Palos"33

Hasta las referencias literarias o más bien metalingüísticasnos evocan esa violencia: "Domina el modo octóstilo, que cuando acometas otro género literario, sea poesía, prosa u otro cualquiera, tus látigos dejaran cicatriz, y tus bofetadas, marca." ${ }^{34}$

\section{La mujer y las pasiones mundanas}

Shakespeare dejo escrito en su conocido soneto 116 lo siguiente: Love's not Time's Fool.

Pero en El Bosque de los letrados la locura amorosa suele estar reducida a lo utilitario y abundan comentarios despectivos hacia las mujeres como el de aquella casamentera "sobrada de pies" y así sucesivamente.

Cuando Ji Weixiao le pide a Du Shaoqing que tome una concubina "linda y discreta", éste le responde, negativamente:

"Además, el concubinato es contrario a la voluntad del cielo, pues los seres humanos son finitos, y si un hombre se le da por tener unas cuantas mujeres, habrá quienes se queden sin esposa (lo que justamente ocurre ahora en China pero no por el concubinato, sino por la política de natalidad). Vuestro hermano menor elevaría a la Corte una propuesta de ley para que solamente se permitiese tomar concubina y no más de una, al hombre que a los cuarenta años aún no tenga hijos; y si la concubina no se los da, que la case con otro antes de retenerla para sí, pues de este modo no habrá hombre sin mujer, o serán pocos los que no la tengan, y se reforzarían los principios vitales." 35

\footnotetext{
33 WuJingzi (2007):114

34 Wujingzi (2007):146

35 WuJingzi (2007):409
} 
Es cierto que en la obra, el concubinato, el proxenetismo y la prostitución son rutinarios, pero al final hay una excepción importante, el personaje de Doncella Galana, del que el protagonista queda prendado por su belleza e inteligencia.

"Doncella Galana se desvistió y acostó; era lustrosa, como toda músculo, y cimbreña como nada hueso y los dos holgaron en muy buena armonía." 36

"Doncella Galana cantará para vos, que en todos los Doce Pabellones no hay otra que entone tan bien los Tres Aires de QingPing, del poeta Li Bai" ${ }^{37}$

Como se aprecia esta protagonista sabe de la poesía clásica, juega a las damas y tiene profundas creencias religiosas, algunos letrados gustan de leerle sus versos y a su vez se regocijan por la apreciación de los mismos.

Pero como se anuncia al final del antepenúltimo capítulo, el 53, Doncella Galana anhela entrar en el monasterio de Benhui pues lo ha contemplado en un Sueño y allí se retira a pasar sus días, frustrando los poco atinados intentos del protagonista.

Camina por los montes de Fujian

Un caballero de ánimo errante;

Acaba metida en un monasterio

Una dama de atractivo talante. ${ }^{38}$

Cuando por fin descubre que el amor le ha fallado, y el confucianismo se está olvidando entre templos cubiertos de hierba, la razón es inimaginable parece que el autor encuentra su propio centro del laberinto, su respuesta personal al enigma, pero sólo lo sugiere mediante "el tañido del salterio" dejando un final abierto para la imaginación y el contraste del lector.

\section{Renunciando al mundo}

En efecto, retirarse a tañer música es el comienzo de la renuncia Confuciana, como leemos en el Zhuangzi.

La canción de despedida nos recuerda que todo pasa y nada es permanente, ni el título, ni la fama, la riqueza o la posición.

Algunos de los temas que indican esto de modo inequívoco son, despojarse de las ropas de la oficialidad, lavarse los pies en el río Canglang, o adorar al rey del Vacío en compañía de un horno de alquimista y sutras Buddhistas.

El autor nos sorprende entonces con la pregunta retórica:" ¿Será posible, discreto lector, que de acá en lo por venir no haya hombre virtuoso que entre en el Bosque de los letrado? “.

Cien años pasan volando

¿Por qué tanto sentimiento?

¡Tan arduo es seguir la senda

De los laureles eternos!

Con mi hornillo para hierbas

$Y$ mis libros para el rezo,

Al Principe del Vacio

Honraré en lo Venidero

\section{Conclusiones}

La obra revela en definitiva la estética china como una suerte de laberinto o enigma con el que quisiéramos cortar, rompiendo con tanta insensatez, pero nos vemos impotentes para hacerlo. Desde luego si este texto responde a la realidad de la sociedad de esa época y no hay

\footnotetext{
36 WuJingzi (2007):622

37 Wujingzi (2007):624

38 WuJingzi (2007):623
} 
muchas razones para dudar de que fuera así, justificaría cualquier tipo de Revolución y por supuesto la supresión del obsceno Sistema de Exámenes y Oposiciones.

Por la opresión y el sinsentido que transmite el texto, podemos relacionarlo fácilmente con escritores como Franz Kafka (Beim Bau der Chinesischen Mauer, 1917) o Milan Kundera (La insoportable levedad del Ser).

Se trata de un juego ilusorio de espejos o más bien de un camino de senderos que se bifurcan y esto se aprecia también por la forma de concatenar anécdotas o biografías, que obligan a seguir un hilo, una falsa pista, que al final no tiene solución.

No hay nada confiable en este simpar Retablo, ni hombres ni mujeres, plebeyos o letrados, confucianos o buddhistas, la realidad es eternamente mutable, caleidoscópica y fractal. En una abrir y cerrar de ojos (in ictu oculi) todo desaparece, se reinventa y estamos ante una escena nueva. Es como un tapiz viviente, un bosque compuesto por miles de troncos, ramas y hojas, una realidad arborescente y de ahí se explicaría el título de Rulin o Bosque de los Letrados.

En ese sentido nos reafirmamos en el substrato taoísta, pues lo que caracteriza a la Naturaleza en el Dao De Jing, (literalmente La Verdad de la Naturaleza según los filósofos modernos chinos) es el encuentro de paradojas en su seno por la mutabilidad. El Ser Humano sólo puede disolverse en el Cosmos en una fusión total.

En este caso las paradojas de la Naturaleza o si queremos del Bosque, se han llevado al plano de Vidas Humanas absurdas, por ello el contraste no surge por designio supremo, sino por la necedad o la maldad de los personajes.

Es cierto que se trata de un asombroso retrato costumbrista, un gran anecdotario o hasta un refranero culto, aunque en mi modesta opinión muchas expresiones no estén bien explicadas a pesar de la gran cantidad de notas.Se dice por ejemplo en un banquete que degustan "pulmón marino", ipero así es como se llama a la carne de medusa! muy común hoy en toda la cocina de inspiración asiática.

Las anécdotas se suceden entrelazándose con biografías de personajes o autobiografía del autor. Son Vidas Paralelas, pero la Razón queda fuera de lugar en esta "Historia marginal del Bosque de los Letrados".

Si hay algo que atestigua la obra es el fracaso del raciocinio y lo imposibilidad del anhelo humanista, ejemplificada en la ruina del Templo de Taibo. Esto viene a contrastar abruptamente con lo expresado por Voltaire sobre Confucio en la misma época de publicación del Bosque de los Letrados:

Confucius

De la seuleraisonsalutaireinterprète

Sans éblouir le monde, éclairant les esprits

Ilne parla qu'ensage, et jamais en prophète;

Cependanton le crut, et même en son pays

Toda dignidad que los personajes hubieran intentado aparentar durante una etapa previa se disuelve ahora en sordidez.

El relator se convierte en un precedente del Fausto que no entiende al Mundo (Ya sabemos que Goethe fue un gran admirador de la cultura oriental a la que sin embargo consideraba enferma y desequilibrada).

Por tanto el logro fundamental de WuJingzi sería su control de la dimensión espaciotemporal. Logra detener el Tiempo y que las generaciones pasen en un suspiro como si nada hubiera sucedido, pero ahí perduran las Ruinas del Sueño, como en el Angelus Novus de Paul Klee, comentado por W. Benjamin, el relator quisiera detenerse a restañar heridas y oficiar funerales, pero un poderoso viento del futuro le empuja irremisiblemente, su hora ya está cumplida, su época ha pasado.

Como escribiera Giorgos Seferisen Solsticio de Invierno: "Amanecer de un día, que creíste que salía el Sol”. 
Este desaforado esfuerzo, de tan singular maestría por congelar en ámbar el instante, no se producirá en la literatura hasta mucho más tarde, posiblemente con Joyce o el Witold Gombrowicz de Ferdydurke o Transatlantyk.

Para representar este Aleph, no nos bastará ya con el Teatro, ni siquiera un teatro barroco de bastidores ${ }^{39}$.

En función de lo aportado por WuJingzi ¿Cómo habremos de vivir?

Desconfiando de toda condición humana, aceptando lo infinito del espacio-tiempo y ocupando su extensión, aferrándonos a las adumbraciones de la Nada, desintegrando nuestro Ser en plena Naturaleza.

Recorrer el laberinto comprendiendo su futilidad es renacer en la auténtica Sabiduría:

吾唯足知

Pues como dice el ritornello buddhista: Conozco sólo cuanto es suficiente.

Zhuangzi, en su libro 6 definió así a esta Verdadera Persona:

El verdadero hombre de la antigüedad no conocía el amor por la vida ni el temor a la muerte. Tomaba la vida sin deleite y la abandonaba sin resistencia. Tranquilamente llegaba y del mismo modo se marchaba. No olvidaba sus comienzos ni exploraba su fin. Aceptaba la vida con gusto y olvidándose del temor por la muerte volvía al estado anterior a la vida. No utilizaba la mente para rechazar el Daoni utilizaba su confianza en el hombre para ayudar al Cielo. A esto es a lo que llamo el verdadero hombre.

古之真人，不知说生，不知恶死。其出不欣，其入不距。翛然而往，修然而来 而已矣。不忘其所始, 不求其所终。受而喜之, 忘而复之。是之谓不以心捐道, 不以人助天，是之谓真人。

(Sed infinitos como el espacio y las cuatro direcciones -éstas no tienen límites y no forman recintos. Sostened todas las cosas en vuestro amor).

\section{Epílogo}

Hacia la misma época en la que suponemos que se compone El bosque de los letrados (1750), el milanés Giuseppe Castiglione (cuyo nombre chino fue LangShining郎世宁) junto con otros trabajadores europeos y chinos, diseñó y construyó en el Palacio del Yuan Ming Yuan (圆明园) en las afueras de Beijing, un conjunto de edificios entre los que se encontraba un jardín de flores en forma de laberinto de terracota, para el Emperador Qianlong (fig.1).

En 1861, tropas anglo-francesas comandadas por Lord Elgin y el coronel Dupin redujeron a cenizas los palacios europeos del Yuan Ming Yuan, concebidos por el genio del artista sino-europeo. Ésta fue la penúltima represalia de la guerra del Opio.

Sorprendentemente, el laberinto quedó intacto.

No obstante, tal destrucción fue lamentada por Victor Hugo, el mismo que hizo escribir la palabra Ananke (Fatalidad) a Dom Claude sobre los muros de Nôtre-Dame, en una emotiva carta enviada al capitán Butler.

Ante uno de los edificios tristemente desaparecidos, el HaiYangTang o sala del Mar Calmo, Castiglione ayudado por Benoit confeccionó un famosísimo reloj de agua con los doce animales del horóscopo, que arrojaban chorros por su boca sobre una campana broncínea para marcar las horas. A las doce del mediodía todos los animales espurreaban agua a un tiempo (fig.2).

Como es sabido, dos de las cabezas de bronce de éstas esculturas mitológicas, robadas por las tropas francesas, y hasta entonces pertenecientes a la colección privada de Yves SaintLaurent, se subastaron en el año 2009 en Christie's de Paris por un importe total de 60 millones de euros.

J'espère qu'un jour viendra où la France, délivrée et nettoyée, renverre ce butin à la Chine spoliée.

Victor Hugo

(C) 2017 Ioseph Cabeza-Lainez

${ }^{39}$ El serial televisivo es el formato al que con mayor éxito se ha adaptado "El bosque de los letrados" 


\section{Bibliografía escogida}

Almodóvar Melendo, J.M/ Cabeza Laínez, J.M. (2002): “La expansión ibérica, germen de la razón barroca". En Revista de historia y teoría de la arquitectura No 2-3, 2002, pp. 274-307

Regalado, Antonio (1995): Calderón. Vol. I. y II. Barcelona: Ediciones Destino libro.

Borges, Jorge Luis (2012). "El jardín de senderos que se bifurcan”. En Ficcciones. Barcelona: De Bolsillo.

Spence, Jonathan(1985): The Memory Palace of Matteo Ricci.New York: Penguin.

Buci-Glucksmann, Christine (1984): La raison baroque: De Baudelaire à Benjamin. París: Galilée.

GaoXingJiang (2003): El libro de un hombre solo. Barcelona: Ediciones del Bronce.

Quevedo, F. :Sueños y discursos. Consultado en:

https://www.unav.edu/centro/griso/files/file/materiales_docentes/Suennos_Quevedo .pdf el 30/11/2017

Slupski, Zbigniew (1989): “Three Levels of Composition of the Rulin Waishi". En Harvard Journal of Asiatic Studies, Vol. 49, No. 1 (Jun), pp. 5-53.

Qichao, Liang (1902): On the Relationship between Fiction and the Government of the People. (reimpreso en ZGJDWLX 1: 157-61). Disponible en: https://es.scribd.com/document/350509925/Liang-Qichao-On-the-RelationshipBetween-Fiction-and-the-Government-of-the-People-Tr-G-N-Cheng Consultado el $01 / 12 / 2017$

Wujingzi (2007). Los mandarines. Historia del bosque de los letrados. Barcelona: Seix Barral

Zhuangzi. Zhuangzi. Editor Dr. Donald Sturgeon. Harvard University. Consultado en http://ctext.org/zhuangzi el 30/11/2017 